\title{
Global Standardization Education Program Collaborated by Osaka Univ. and MJIIT, UTM
}

\author{
Hiroshi Nakanishi ${ }^{1}$, Rozhan Othman ${ }^{2}$, Kunio Igusa $^{2}$, \\ and Shozo Komaki ${ }^{2}$
}

${ }^{1}$ Osaka University, nakanishi@idiscp.osaka-u.ac.jp

${ }^{2}$ Malaysia-Japan International Institute of Technology, Universiti Teknologi

Malaysia,rozhan@ic.utm.my,kunigusa@gmail.com,komaki@ic.utm.my

Received 27 March 2013; Accepted 14 May 2013

\begin{abstract}
In Osaka University, the Education on Global Standardization Program (UnivEoGSz) for post-graduate students is offered by the Interdisciplinary Center of Osaka University and extensively developed since 2009. The Malaysia-Japan International Institute of Technology (MJIIT), Universiti Teknologi Malaysia (UTM) is now going to setup the courses of standardization education as a sub program in collaboration with Osaka University for Malaysian academics and university students. In this article, the objectives and frameworks of this global standardization education program will be evaluated, especially on the existing Osaka Univ. program and MJIIT program. The general issues on standardization education and the results of case studies on the current trends of global standardization are discussed. The contents of Osaka Model, which MJIIT is now adopting, are slightly different from the conventional educations regarding the introduction of standards, which was architected for the general local schools and companies. It is expected that the article will give a valuable example for understanding on the future direction of standardization educations and advance further its activities in academic and/or university on the issue. And by promoting this education, we hope the conceptual paradigm regarding standardization will be shifted from the just simple international standardization, as reflecting international expansion of the intellectual property right (IPR) based national standard, to global
\end{abstract}

Journal of ICT Standardization, Vol. 1, 59-82.

doi: 10.13052/jicts2245-800X .124

(C) 2013 River Publishers. All rights reserved. 
standardization, as commonly acceptable one beyond IPR. And it focuses more enhancing the innovativeness, entrepreneurial and global standardization activities as well.

Keywords: Education on Global Standardization, Generic, Academic, University.

\section{Introduction}

There has been considerable effort in expanding standards education programs by the various local standardization bodies. This includes programs offered by national standardization bodies, industry supported consortium/forums and internal organization of industries. In the past, these programs are provided to companies and local schools, and were mainly focused on the educating students and trainees of the established or revised standards and their certification process. This includes standards set by national and/or international standardization bodies.

Development of such standards were mainly generated based on the interests of limited number of nations or companies, which have already developed and locally/nationally implemented products based on their intellectual property rights (IPR). These standards are referred to as international standards (IS). In recent years, the World Trade Organization (WTO) issued technical barriers of trade (TBT) and fair, reasonable and non-discriminatory licensing (FRAND/RAND) and this ruling is applied all over the world. Under this ruling, developed standards are referred to as global standards (GS) and not international standards, because the role of IPR is given less emphasis and national standards have less importance. So the global standardization (GSz) activitiesis become more important than IPR and national standards (NS) setup. Under these situations, standardization activities meet paradigm shift from IPR and NS oriented international standardization to global standardization oriented activities. After paradigm shift, ongoing standardization with development is required and global discussions among global interested parties are inevitable. This is called as Global Standardization (GSz), not international standardization (ISz).

Education on standard setting to companies and schools in Japan also reflects this paradigm shift. The earlier standard education has been mainly focused on the propagating the established standards and certifications. This had in the past been referred to as education on international standard for industry (Industry-EoIS). After the paradigm shift, education on global stan- 
dardization for academic members and university students becomes more important to fit for the ongoing standardization with development. We call this as Education on Global Standardization for University (Univ-EoGSz), and set up the program and courses under the collaboration with MJIIT, UTM and Osaka University.

In this article, section 2 describes the importance and objectives for standardization education in/for faculty members and university students. Section 3 introduces the Osaka University's global standardization program for post-graduate students, which contains several courses relating with global standardization. Section 4 introduces the global standardization education subprogram, which is now planning to introduce in MJITT, UTM through their collaboration with Osaka Univ. Section 5 introduces the relationship between Malaysian national standardization bodies and global standardization bodies, and also our planning sub-program. This article is not a technical paper, however it is focused on education on global standardization in/for university (Univ-EoGSz), and it will become important activity after the paradigm shift in standardization.

\section{Objectives for Standardization Education in University}

\subsection{Paradigm Shifts in Standardization}

The history of standardization can be traced back to the ancient civilizations of Babylon and early Egypt. The earliest standards used were the physical standards for weights and measures. By the time of the Industrial Revolution in the early nineteenth century, standardization played on important role in ensuring high accuracy and reliability of parts and system compatibility in mass production. Over the past 100 years, standardization has expanded to include products and manufacturing activities. Standards became important in enabling businesses to exploit their business innovations through IPR. Now a days, standardization activities are focused on the products. These are done based on the IPR owned by firms to enhance their commercialization. In these situations, standardizations efforts are started after the final stage of product development or after the local and/or national market implementation.

The evolution of standardization educations over the last 100 years can be summarized as follows:

- Standard based on their IPR is developed after development and real use in national or local market. In this approach, emphasis is given on exploiting IPR, NS and for commercial purposes and profit. 
- The development of de jure and international standardization (ISz) for international market expansion and protection, based on national standard (NS).

- "How-to" approach that utilizes developed standards to facilitate and certificate on their job and developed IS education by companies or local standard bodies.

- The establishment of numerous standard bodies for every specific standard items and areas.

Nevertheless, standard setting is not without setbacks. Some standards led to adverse consequences. Some examples are:

- Tragedy of anti-commons, and/ or exclusive use of their own IPR

- GALAPAGOS syndrome: this is a situation where a local standard may lead to success in local market but fails to make a product successful overseas. As a result, the product fails to reach economies of scale.

- Not Invented Here Syndrome: some standard sets are not accepted by firms and as a result there is little buy-in and adoption. These firms give a cold response to these standards because they are not seen as reflecting the interest of others.

Recent developments show that the rapid change of technological progress is making the life of standards short.This makes the cost of developing standards and the related technologies more costly. As such, it is necessary to ensure that these standards and the related technologies are accepted and diffused quickly and extensively in markets. In addition, the WTO/TBT agreement and FRAND condition enable the fast diffusion of the IPR and enables the recovery of the cost associated with the development of the IPRs and their standards. To be more effective in doing this, global standardization should be proactive and begin much earlier i.e. during their research and development stage. This is especially important, in information and communication technology (ICT) area. This is fast becoming the trend because of the concept of software based upper compatibility and universal and LSI based digital hardware platform, those are developed by the academic and university members, such as Institute of Electric and Electrical Engineers (IEEE) and Internet Engineering Task Force (IETF) etc. De-facto, or forum standards are also becoming more important.Their standards activities are having an impact on how standard setting is done in global standardization body, such as ITU now [1]-[5]. Such a trend of from "Standardization after development" to "Standardization before development"created the paradigm shift as shown in Figure 1. This trend is also shown inshift from"international standardization 


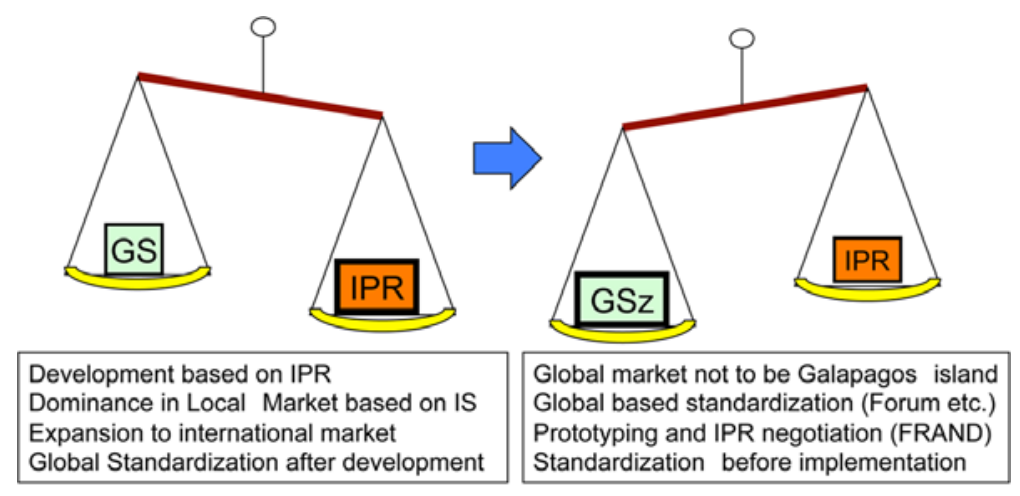

(a) Standardization of past 100 years

(b) Recent standardization after paradigm shift

Figure 1 Paradigm shift in global standardization activity.

(ISz) after setting up national standards" to "global standardization (GSz) without becoming national standards".

This shift leads to the focus away from merely the exploitation of IPR to the GS. Because of this, a discourse on standardization education among academicians and universities is needed and necessary.

"Why Education on GSz is required for academia and university"are discussed [4, 5], and setup Univ-EoGSz [11]-[12]. These trends and objectives are summarized as follows.

- GSz are on going with research and before the start of the development stage.

- Standardization activities should be run concurrently with there search stage.

- Recent standardizations are proactive. (What is required, and Why? Not How-to).

- Research activity, i.e. standardization, is essential in creating leading edge global technologies.

- Role of academians and universities in the research stage is inevitable for global standardization.

- Standardization need to begin with discussion and harmonization among community/countries first and not with companies first.

- Forum/De-facto standardization can emerged first and then move to become de jure .

- EoGSz among academia and universities, where the leading edge technology is developing, is key issue after paradigm shift. 
- Role of academic members, such as IEEE etc., are important for the state of user's view

- IEICE Japan also aware about GSz activity and EoGSz.

\subsection{Target of EoGSz and University Relevance}

Target of the EoGSz will be classified by the 5 categories, as is shown in Figure 2. This section describes why university fits for these activities.

(1) Core \& generic GSz Program for University Students

Education program on global standardization for academicians is better to be generic in its content, because they are not involved in specific standard items and bodies. Academic researchers and university students will start from basic and generic matter and bird watch of standardization bodies is required for them. This core and generic standardization education can

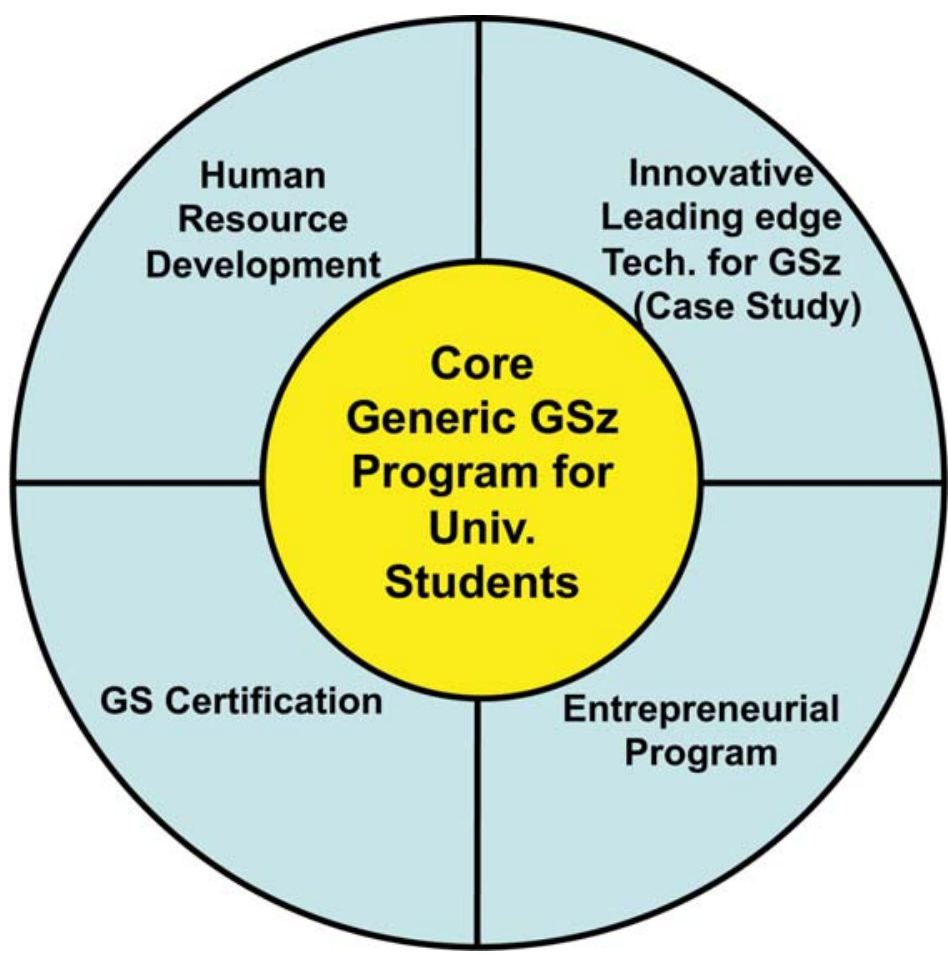

Figure 2 Objectives of education on global standardization for academic and university (UnivEoGSz) 
be incorporate in courses and programs on management of technology. In addition, basic skills required for standardization, such as communication, negotiation, IPR and legal matters, are also responsibility of business related division in university. In this case, project based learning (PBL) can be an effective method for teaching such knowledge.

(2) Innovative Leading Edge Technology (Case Study)

Academians and research staff of universities involve in research on leading edge technologies should includes standardization concerns into considerations at the research stage. Leading edge technologies such as, ex.iPS cell that was awarded Nobel Prize last year, should incorporate the standardization process to balance between social happiness and industry business. Academic members involved with this leading edge research can take the initiative to address standardization issues at the R\&D stage. EoGSz is one of the powerful solutions. Knowledge of case studies of established standard and their standardization process are valuable for academic staff and students to start new standardization.

(3) Entrepreneurial Program

In various universities, entrepreneurial development programs are offered for participants for industry and students. In these programs, addressing GS and IPR issues are necessary to help participants understand how to ensure success in their entrepreneurial business. In the case of new business start-ups and the introduction of new technologies, GSz activities should be a part of the strategic thinking in planning for expanding into the global arena.This should be a part of the entrepreneurial development programs that is offered to students, businessmen, and the public in general, through the involvement and coordination between universities, industry and society.

(4) Human Resource Development for Industry and Society In order to support the new paradigm in GSz, it is important that university students are given the necessary knowledge and know how related to new GSz. Only with this understanding will they be able to contribute to the process of incorporating standardization concerns at the research stage. This is especially important in the research activities done in universities and other public research institutions. This know how will enable to contribute towards global standards development.

(5) Global standardization Certification

In addition to the previous point, the paradigm shift in GSz requires that research organizations including universities have the necessary equipment for their R\&D activities and that these equipment are cer- 
tified according to global standards. Academicians and universities can also play the role of certifying labs, products and equipment based on global standards. They could be used for measuring the newly developed standard value and certification in tern. University and academia also has neutral position and regal mind to perform these certifications.

\section{Global Standardization Education Program in Osaka Univ}

The design of the Global Standardization (GSz) education program at Osaka University is based on the university's system that allows students to enroll in Major and Minor studies.

Section 3.1 describes Osaka University's standardization education program and how it is offered in relation to the Major and Minor studies. Then, design of the standardization education program is described.

\subsection{Osaka University Graduate School Education System - Major and Minor}

Osaka University consists of 17 Graduate Schools, which cover all areas of disciplines, and is based on 3 ideas on education in addition to higher scholastic achievement and specialized knowledge mastering. These 3 ideas are:

[Goals of Major studies]

(1) Comprehensive Understanding

The ability to make sound social judgments and taking a broad perspective.

(2) Synthetic Imagination

The ability to create a network that ties together people from different fields and social standings

(3) Transcultural Communicability

The ability to communicate with and understand people from variousbackgrounds and cultures

To embody this, Osaka University is offering Major and Minor education system.

a. Gain a high level of specialized knowledge and develop ability to under take research 
b. Gain understanding of scientific methods and the ability to utilize science

[Goals of Minor studies]

1. Credits requirement for major study completion

2. Credits requirement for minor study completion

a. Cultivate a broad perspective of issues that integrates an interdisciplinary point of view

b. Develop ability to understand societies and the world

c. Develop an appreciation sense of events and opinions

Every graduate student takes their required master or doctor course of at the graduate schools where they are enrolled. Graduating requirements for master courses are 30 credits or more.

Optionally, every graduate student can take one or more of the interdisciplinary education programs.

Osaka University has been offering many interdisciplinary education programs for the minor studies since 2004. Forty six interdisciplinary education programs were offered in 2012 academic year. Each interdisciplinary education program has a subject matter and consists of multiple courses offered in different graduate schools. They are categorized into 2 education programs as in the following.

- Graduate Program for Advanced Interdisciplinary Studies

Requirements for completion are 8 credits or more.

- Graduate Minor Program

Requirements for completion are 14 credits or more.

The Major and Minor education system is shown in Figure 3.

\subsection{Design of Global Standardization Education Program}

It is important to understand the human resource requirements for a Global Standardization. It is not enough that instructors have the knowledge on standard setting and intellectual property. Instructors must also understand how standards setting is linked to business issues. They must also develop the abilities related to negotiation and communication with people from different background and cultures.

(1) Designing global standardization education program for graduate students 
Major Study is consisted of the required courses by graduate school. Minor Study is consisted of the selected courses by sponsoring faculties.

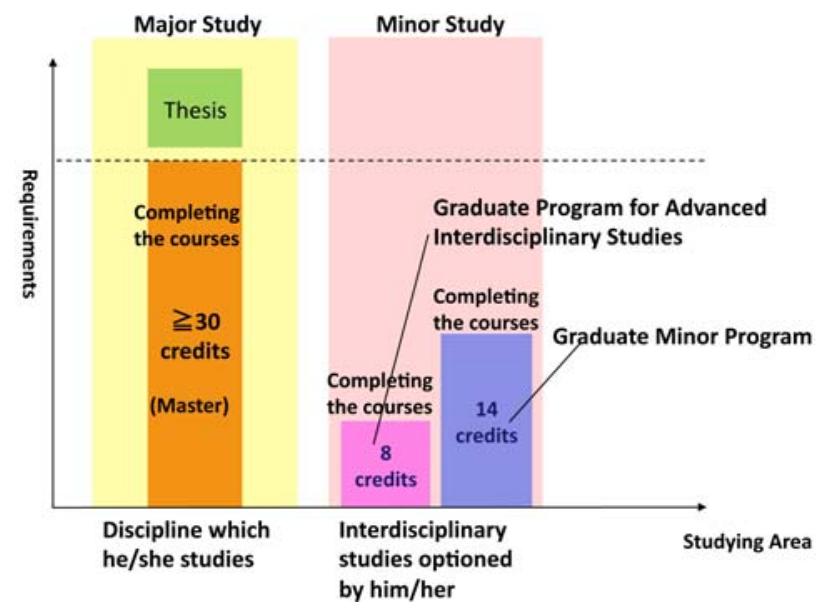

Figure 3 Major and minor education system and their credits requirements.

a. Program Target Students:

Graduate students (reason: enough time for learning subjects and high ability of understanding for study and development)

b. Program Objectives:

Program to offer "knowledge concerning standardization" plus "knowledge concerning negotiation and management"

c. Program Design

The $1^{\text {st }}$ step: To decide "the body of knowledge concerning global standardization" that the program would offer.

The $2^{\text {nd }}$ step: To select several courses which are suitable for offering "the body of knowledge concerning global standardization.

The body of knowledge in the $1^{\text {st }}$ step consists of "knowledge concerning global business, standardization, and management", "knowledge concerning standardization in information and communication fields", "knowledge concerning standardization in the manufacture field", "knowledge concerning intellectual property", "knowledge concerning knowledge value society" and "knowledge concerning negotiation".

To decide the courses in the $2^{\text {nd }}$ step is done based on the body of the knowledge in the $1^{\text {st }}$ step, the syllabus of the university of their own and other universities. 
Figure 4. shows the courses included the Global Standardization program.

\section{(2) Implementation of the global standardization education program}

Since 2011, the program has been offered to graduate students. Many students take courses in the program. In 2011, 212 graduate students took these courses and in 2012 another 187 graduate students took these courses. These numbers are quite satisfactory.

\section{(3) Evaluation of the effects of the education of the standardization program}

To evaluate the outcomes of the education of the standardization program, questionnaires were sent to the students of standardization program. This consists of two questionnaires:

a. Questionnaires

Questionnaire A: The knowledge students acquired by learning the subjects

Questionnaire B: The likelihood they will be able to utilize the knowledge in their own carriers in the future

b. Response instruction

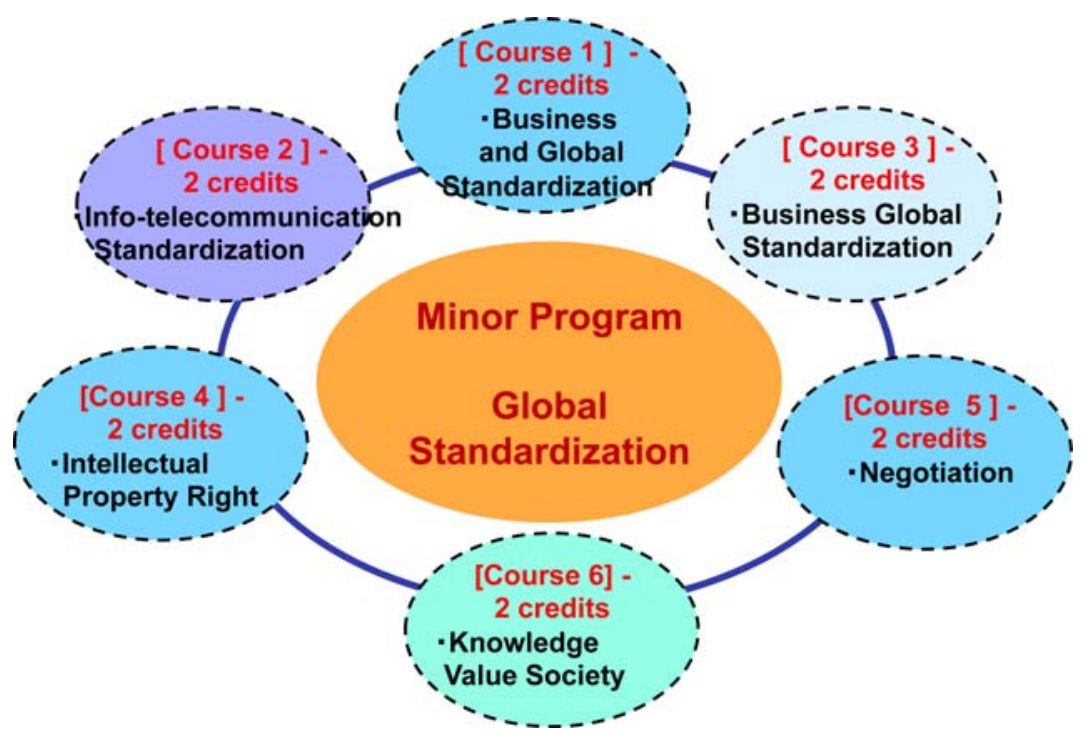

Figure 4 Courses constitution of the global standardization education program. 
Students were asked to choose from several responses for both questionnaire A and B (multiple answers available)

Results of the questionnaires and answers are shown in Table 1 and can be summarized in the following.

(1) Acquired knowledge by learning the subjects; "meaning of global standardization", "items as objects of global standardization", "process to global standardization", "relationship between global standardization and corporative management strategies", "approach to global standardization", "quality of individuals necessary to approaching global standardization", "situation of approaching global standardization in Japan", "items which need new global standardization", "new research issues" and "others" are chosen as answers.

Table 1 Questionnaire results

\begin{tabular}{|c|c|c|}
\hline \multicolumn{3}{|c|}{$\begin{array}{l}\text { Questionnaire A: Which type of knowledge did you gain by learning the subjects? } \\
\text { (Multiple answers) }\end{array}$} \\
\hline \multicolumn{2}{|r|}{ No. Answer alternative } & $\begin{array}{l}\text { Quantity of } \\
\text { response }\end{array}$ \\
\hline & Meaning of global standardization & 22 \\
\hline & Items as objects of global standardization & 9 \\
\hline 3 & Process to global standardization & 15 \\
\hline 4 & $\begin{array}{l}\text { Relationship between global standardization and corporate management } \\
\text { strategies }\end{array}$ & 12 \\
\hline 5 & Approach to global standardization & 13 \\
\hline 6 & Quality of individual necessary to approaching global standardization & 8 \\
\hline 7 & Situation of approaching global standardization in Japan & 16 \\
\hline & Items which need new global standardization & 1 \\
\hline 9 & New research issues & 1 \\
\hline 10 & Others & 0 \\
\hline \multicolumn{3}{|c|}{$\begin{array}{l}\text { Questionnaire B: How do you utilize the knowledge you gained by learning the } \\
\text { subjects to your future carriers? (Multiple answers) }\end{array}$} \\
\hline \multicolumn{2}{|r|}{ No. Answer alternative } & $\begin{array}{c}\text { Quantity of } \\
\text { response }\end{array}$ \\
\hline & Planning for future research themes & 0 \\
\hline 2 & Working for global standardization activities in the working place & 11 \\
\hline 3 & Planning and development for products and services in the working place & 13 \\
\hline 4 & Planning for management strategies in the working place & 7 \\
\hline 5 & Employee training and development of human resources in the working place & 11 \\
\hline & Making use of one of your wide range of knowledge & 6 \\
\hline & Others & 0 \\
\hline
\end{tabular}


(2) How to utilize the knowledge to their own carriers in the future; "planning for future research themes", "working for global standardization activities in the working place", "planning and development for products and services in the working place", "planning for management strategies in the working place", employee training and development of human resources in the working place", "making use of one of your wide range of knowledge" are chosen as answers.

c. The effect of the program

Educational contents are as well understood and the effect can be said increasing.

\section{Education on Standardization at UTM.}

\subsection{Challenges in Introduction of Standards and Education on Standards}

In the case of Malaysia, efforts to introduce standards education in universities by the Department of Standards Malaysia (DSM) has received mixed reactions from universities. Some universities, especially newer ones, are more receptive to the idea and sees standards education as a source of differentiation. Some of the universities that are more receptive are also those who have a history of offering programs in quality and standards. Those universities that are more reluctant to adopt standards educations feel that the current curriculum in their respective universities already have many course work requirements and this leaves little room to include standards education.

In addition, standards education has not inspired interest because it is largely seen to be about standards and rules, detached from business context of organizations. For many academicians, the various standards introduced by the authorities for tertiary education in Malaysia has created considerable criticism about the amount of paper work they require and the petty rules they involve. As a result, many Malaysian academicians have a less than positive view of standards and view them as a burden.

\subsection{The Business Imperative of Standards Implementation}

Choi and Behling point out that the effectiveness of quality programs is affected by the management orientation of organizations [9]. Whereas some organizations adopt quality programs to enhance their competitiveness, some do so in a minimal manner, perhaps even out of grudging compliance with 
customer requirements. The latter tend to be less effective in their quality programs.

Kanapathy and Jabnoun's examination of the impact of ISO certification among manufacturing firms in Malaysia did not find a positive relationship between ISO certification and performance [10]. It does appear that merely adopting standards is perhaps a necessary but not sufficient condition for many companies. Standard certification such as the ISO is necessary to enter certain markets but by itself does not ensure success in the market.

Othman and Abdul Ghani's study of the supply chain management practice of Japanese companies show that companies like Toyota do not just assess their vendors' standards compliance and certification [8]. More important to Toyota is their quality management system, including the involvement of the vendors' CEO in quality management. This shows that quality output and performance requires more than just standards compliance. Companies need to also understand how standards compliance is linked to the management system.

It is therefore necessary to rethink how standards are diffused and how the subject is taught in universities. As of now, standards education in Universiti Teknologi Malaysia is largely through a course on ISO. This will have to evolve to reflect the current understanding on competitive capabilities. Students need to not only know about standards but also how it relates to competitiveness. Only when this is done will standard education be of more value to students and their potential employers.

\subsection{Making the Education on Standards More Relevant to Potential Adopters}

In order to gain legitimacy and acceptance among companies, standards must be presented as a part of the equation in enhancing competitiveness. Its value must come from more than just a set of rules to adhere to. Businesses want to know how the adoption of standard can help with developing their capabilities. It has to ultimately be linked to the creation of better value and profitability. Standards adoption must be seen as a business issue and not merely about rule enforcement.

\subsection{Linking Education on Standards Adoption with Business Strategy. - MJIIT-Osaka Model.}

A joint discussion between faculty members from the Malaysia-Japan International Institute of Technology at Universiti Teknologi Malaysia and 


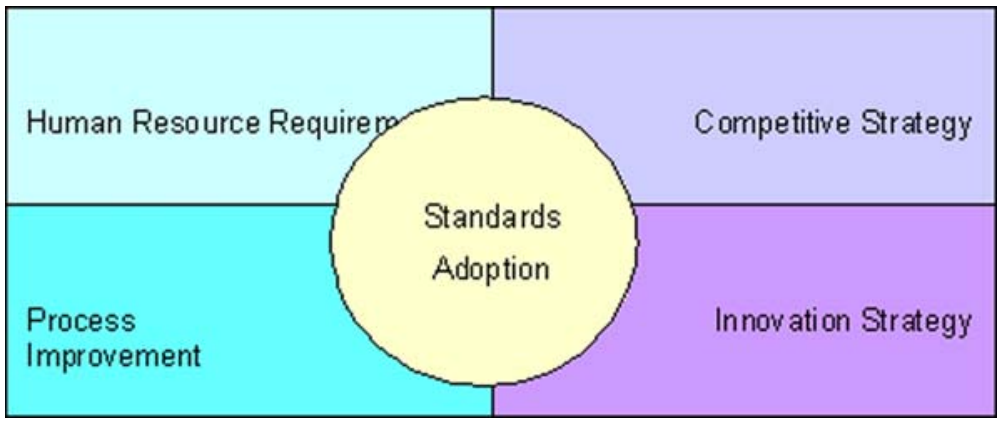

Figure 5 MJIIT-Osaka Standards Adoption Model.

Osaka University's Centre for Interdisciplinary Research and Education led to the formulation of model that reflects the need to integrate standards adoption with business strategy. Figure 5 depicts the model formulated from the discussion.

This model argues that standards adoption can only make a contribution to competitiveness when it fits the company's competitive strategy. The company's competitive strategy, in turn, defines the innovation strategy the firm should adopt. These two decisions then define the processes that need to be in place in the company and how its human resources should be developed.

For example, a Small and Medium-sized Enterprise (SME) in a developing country producing automotive parts may have little or no propriety technology. This leaves the company with no option except to compete as a low cost producer [6]. However, to be selected as a supplier, the customer would usually have a requirement that the company comply with certain standards such as the ISO and TS standards. Attaining certification is a necessary condition but it is not enough for the SME's long-term competitiveness. In addition to low cost, they need to also provide consistent quality and deliver on time [7]. To do this, this SME will need to focus on innovation that increases its efficiency. Typically, this would involve process improvement and may include adopting lean production techniques. To support all this, the SME has to ensure that its human resource has the skills needed to produce at the cost and quality desired by the customer and deliver them on time. At the same time, as a low cost producer, the SME will not invest too much in training beyond what is needed to support its production requirements.

Another example are companies producing smartphones. Change and innovation in this industry is fast and research and development need to move 
at a fast pace. However, doing the full range of research activities needed to create new smartphones is costly and time consuming. As such, many smart phone companies simply purchase technologies that are the de facto standards such the Android operating system and focus on differentiating by developing technologies around the operating system or in integrating acquired technologies. Here the focus of innovation is producing newer smartphones that offer more utility to customers. The process developed by such a company will have to be flexible to enable the incorporation of new technologies and close coordination with customers to understand what customers want. The human resources in these companies are expected to be creative and search for new ideas that will enable the companies to leap ahead of its competitors.

\subsection{Scope and Framework of Standardization Education Program in MJIIT}

Figure 6 shows the basic framework of the standardization education program in MJIIT. The Univ-EoGSz program will be set up as a Sub Program in the Department of Management of Technology (MOT), MJIIT for the Post Graduate students in MOT and also for PG students in the Departments of Electronic Systems Engineering (ESE), Mechanical Precision Engineering (MPE), and Environment and Green Technology (EGT). Special courses on

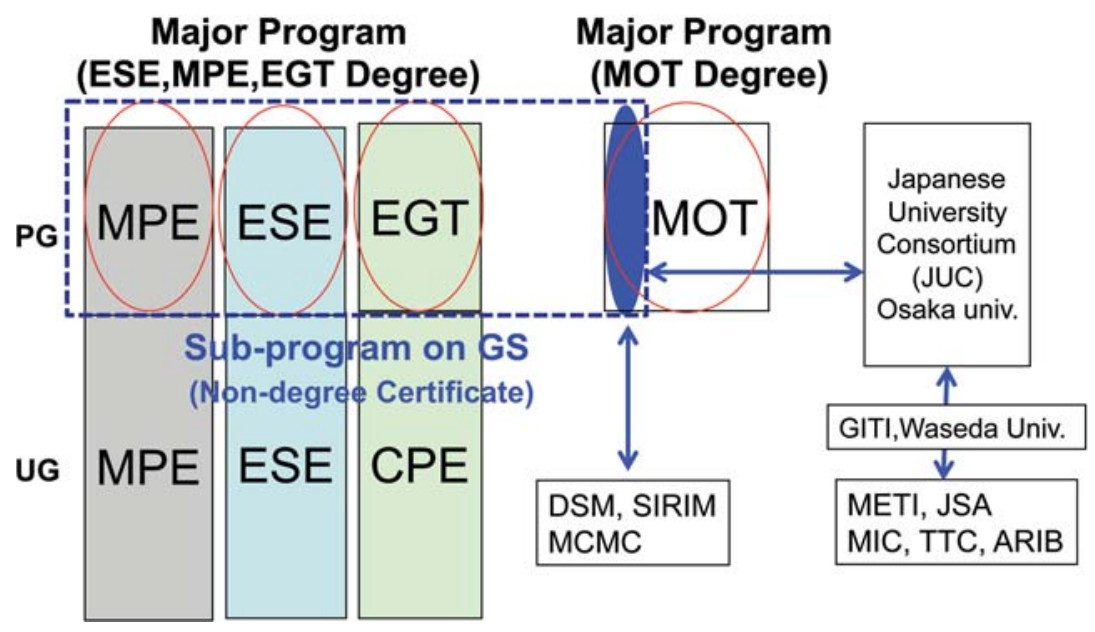

Figure 6 GS Sub-program frame structure. 
Global Standardization Education Program 75

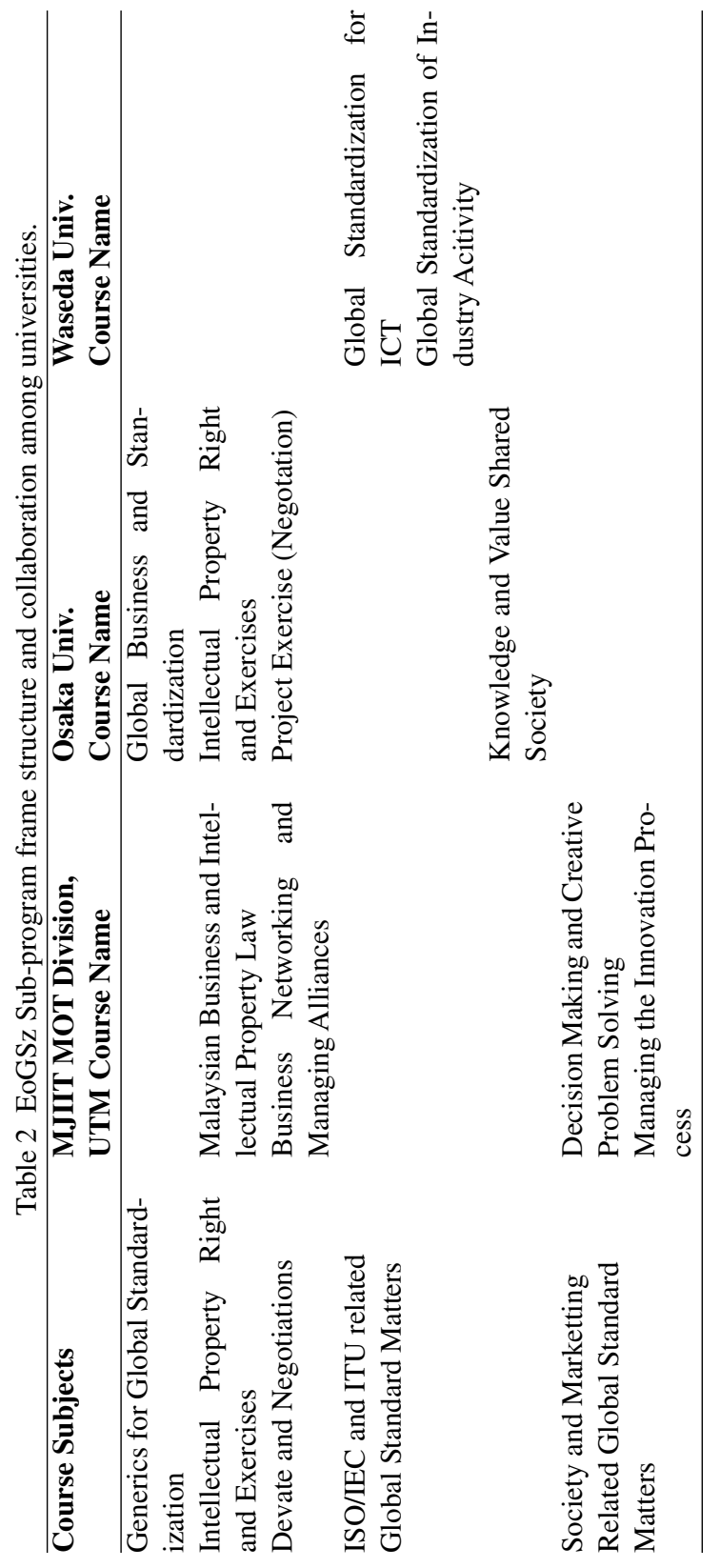


Global Standardization will be offered in MOT in collaboration with Osaka Univ.

Osaka Univ. and MJIIT will award non-degree certificates to students who fulfill the requirements for this program (number of credit, subjects, credit transfer, etc.). The program is also supported by the Japan University Consortium (JUC) that includes 25 Japanese Universities. Some topics on GSz, related to ITU and ISO/IEC are offered by GITI, Waseda University, in collaboration with METI, JSA, MIC, TTC, ARIB in Japan.

Proposed course outline for EoGSz Sub-program is shown in Table 2. This sub-program includes generic components as well as know-how related to standardization. This is because the technology area is spreading over various divisions, as same as the situation in Osaka University's Minor Programs. The required course of EoGSz sub program is offered in a workshop format using Problem Based Learning methodology. Lectures are delivered by Osaka Univ instructors. UTM's MJIIT MOT department offers a number of courses that are similar offered in Osaka Univ., such as IPR, Negotiations, etc. These courses are included the EoGSz sub-program as elective courses. Other GSz related courses, such as decision making matter and innovation process related matter are included in this EoGSz sub-program as elective courses, as well. Those are necessary and generic skills for PBL and global standardization.

\subsection{Relation of Malaysian Standardization Bodies and MJIIT Program}

The relation ship of Malaysia's standardization bodies, such as DSM,SIRIM, and MCMC are illustrated in Figure 7.

One of the institutions designated as a standards setting organization by The Department of Standards Malaysia (DSM), Ministry of Science and Technology Innovation (MOSTI) is the Standards and Industrial Research Institute of Malaysia Berhad (SIRIM). SIRIM is a corporate organisation owned wholly by the Malaysian Government, through the Minister of Finance Incorporated. It has been entrusted by the Malaysian Government to be the national organisation for standards and quality, and has been a participating member in over 80 ISO/IEC Technical Committees and Subcommittees. SIRIM set up Industrial Standards Committees (ISC) related to technical areas, and under ISC, various Technical Committee (TC) and Working Groups (WG) exist.

In Malaysia, standards related to telecommunication and involvement in ITU matters is under the jurisdiction of the Malaysian Communication and Multimedia Commission (MCMC). The MCMC was established 


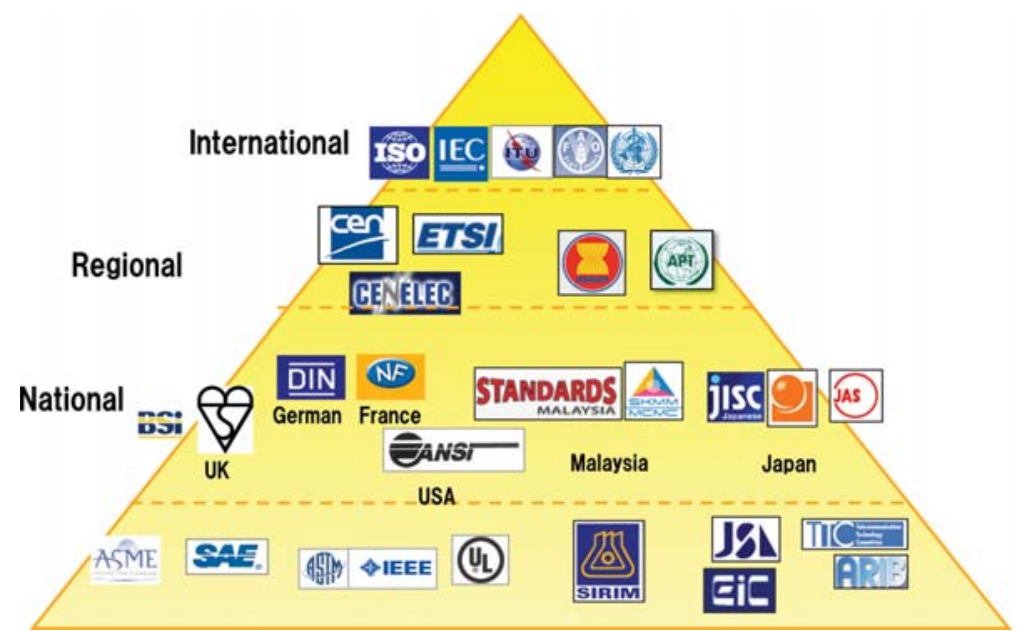

Figure 7 Various Standardization Bodies relating with Malaysia and Japan.

out of the realization and explosion of a new convergent communications and multimedia industry in Malaysia in the mid 1990s, a new paradigm requiring new approaches in media policies and regulation is necessary. MCMC was established under the Communications and Multimedia Act 1998, which set out a new regulatory licensing framework for the industry and the creation of an agency to oversea. The Commission set forth 10 national policy objectives, which is the regulatory framework, which includes economic regulation, technical regulation, consumer protection and social regulation.

For the regional standardization body in Southeast Asia, the ASEAN and Plus Standards Scheme treats standardization matters. In addition, Asia-Pacific Telecommunity (APT), which was founded on the joint initiatives of the United Nations Economic and Social Commission for Asia and the Pacific (UNESCAP) and the International Telecommunication Union (ITU), serves as the focal organization for ICT in this region. The APT has 38 member countries, with 4 associate members and 130 affiliate members. Through its various programmes and activities, APT has made a significant contribution to the development and growth in the ICT sectors. The APT Wireless Group (AWG), formerly known as APT Wireless Forum (AWF) is covering various aspects of emerging wireless systems, and Asia-Pacific Telecommunity Standardization Program (ASTAP) act as to establish regional cooperation on standardization and to contribute to global standardization activities, etc. 
For university and academic members in Malaysia, we are now intending to include case studies of topical, typical and leading edge technology matters, such as recycling and food rerated standards, etc. Such matters are mutually discussed with DSN now. First workshop was held in this April, and discussed the MJIIT-Osaka Standards Adoption Model shown in Figure 5, and started to setup the education on global standard and standardizations into universities in Malaysia.

Another symposium relating with recycling and their standardization will be held in this May at Osaka University with the collaboration between MJIIT and Osaka Univ.

\section{Conclusion}

This article describes the paradigm shift in global standardization, and the shift from "standardization after development" to "standardization before development". The WTO/TBT agreement and FRAND condition enable the fast diffusion of the IPR and enables the recovery of the cost associated with the development of the IPRs. To be more effective in doing this, global standardization should be proactive and done much earlier i.e. during their research and development stage.Then the GSz activity should be done in parallel or in advance during the research and development activities, which is mainly done by the academicians and university researchers. The design of the Global Standardization program is done to fulfil these requirements. This is the approach taken by the Centre for Interdisciplinary Research and Education at Osaka University. Likewise, this is also the approach taken by the MOT Department at MJIIT, UTM.

\section{Acknowledgement}

Authors would like to express our gratitude to Prof. Ir Megat Johari Megat Mohd Noor, Dean, MJITT and member of Global Standardization Action Group, and also experess our gratitude to all the action group members for their valuable suggestions and discussions.

\section{References}

[1] APEC Committee on Trade and Investment, "Teaching Standardization in Universities: Lessons Learned from Trial Program”, APEC SCSC Education Guideline 4 - Case Book,October (2011) 
[2] IEEE, "Standards Education", http://www.ieee.org/education_careers/education/stan dards/index.html

[3] ISO, "Education about standards", http://www.iso.org/iso/home/standards/standards-ineducation.htm

[4] Komaki, S., Kobayashi, Y., "Standardization Activities of the IEICE Japan” (in Japanese), Trans on IEICE Japan, Vol.J89-B, No.2, pp55-67, (2006).

[5] ITU-T, "ITU-GISFI-DS-CTIF Standards Education Workshop", Aalborg, (2012)

[6] Choi, T. Y and Behling, O. C., "Top managers and TQM success: one more look after all these years", Academy of Management Executive, 11:1, pp. 37-47, (1997).

[7] Kanapathy, K. \& Jabnoun, N., "Are ISO 9000 Programmes Paying off for Malaysian Manufacturing Companies?", Malaysian Management Review, December, pp. 40-46, (1998).

[8] Othman, R. and Abdul Ghani, R., "Supply chain management and suppliers' HRM practice". Supply Chain Management: An International Journal, 13:4, pp. 259-262, (2008).

[9] Tatsumoto, H., Ogawa, K. and Shintaku , J., "Standardization, international division of labour and platform business." MMRC Discussion Paper Series, pp.1-17, (2010).

[10] Stone, K. B. , "Four decades of lean: a systematic literature review". International Journal of Lean Six Sigma, 3:2, pp.112-132, (2012).

[11] Komaki, S., "Global Standardization Program of MJIIT,UTM and Osaka Univ.”, ITUGISFI-DS-CTIF Standards Education Workshop, October (2012)

[12] Nakanishi, H.,'Implementation of Education Program on Global standardization for University Students", Joint ITU-IEICE-CTIF-GISFI Workshop on Education about Standardization, April (2013)

\section{Biography}

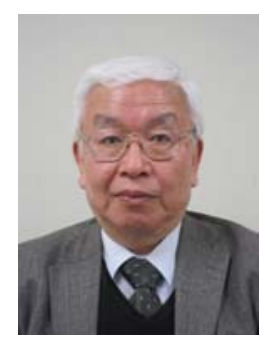

Hiroshi Nakanishi Professor, Osaka University. He was born in 1947. He graduated from graduate school of engineering of Osaka University in 1973 and got master's degree from Osaka University in 1973. He joined ECL of NTT (Electrical Communication Laboratory of Nippon Telephone and Telegraph public corporation) as a researcher in 1973. His major is electronics and information science. He had been researching and developing Magnetic and Optical storage devices, storage systems and network filing systems. Since 2006, he is working for Osaka University as a professor of Centre for Interdisciplinary Research and Education, and is researching designs of interdisciplinary education program through analysis of social needs and is teaching a program of Global Standardization. 
He is a member of The Japan Society of Information and Communication Research and a member of The Institute of Electronics, Information and Communication Engineers of Japan, also a member of The Japan Society for Educational Technology.

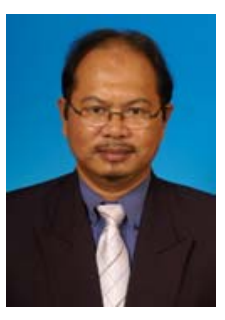

Rozhan Othman Professor MJIIT, UTM. Rozhan Othman is a professor, Department Head of Technology Management, Malaysia-Japan International Institute of Technology, Universiti Teknologi Malaysia, and Chair of Standardization Action Group of MJIIT. He earned his BBA and MBA from Ohio University and his PhD from University College Dublin. His areas of research interest are HRM, Leadership and Strategic Management.

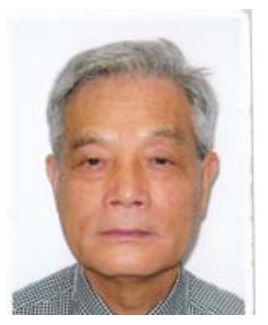

KunioIgusa, Professor, MJIIT, UTM. He was born in 1942. He graduated Tokyo Metropolitan University, Faculty of Economics in 1967. He joined the government research institute named IDE (Institute of Developing Economies) under the METI, Japan. He engaged research work for the government on the Asian economic policy issues and its business affairs for over 35 years. During this period, he had positioned of the Visiting researcher at Gajah Mada Univ.(1974), Research Fellow at the Indonesian Chamber of Commerce (1990), and Visiting Professor of Graduate School of Management at Macquarie Univ. (2000).

In 2001 he has appointed as the Professor of Ritsumeikan Asia Pacific Univ. (APU), being in charge of Asia Economic Management Course, and also served the Dean (2003) of the Faculty of Management of Ritumeikan APU. He has published many books, papers, articles on the Asian economicaffairs and businesses. He is invited to a professor of Management of Technology of MJIIT in 2012. 


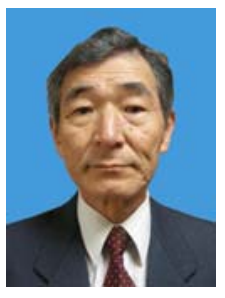

Shozo Komaki Professor, MJIIT, UTM. He was born in 1947. He received BS, MS and $\mathrm{PhD}$ degrees from Osaka University in 1970, 1972 and 1983, respectively. He joined to NTT Electrical Communication Labs.in 1972, where he was engaged in R\&D on digital radio systems. From 1990, he moved to Osaka University and engaging in the research on Radio on Fiber Networks, Wireless service over IP networks, Software Definable Radio Networks and Radio Agents. He is currently a Professor of the Department of Electrical System Engineering, Malaysia International Institute of Technology, Universiti Teknologi Malaysia.

\section{List of Abbreviations}

APT Asia-Pacific Telecommunity

ASEAN Association of South East Asian Nations and plus

ASTAP Asia-Pacific Telecommunity Standardization Program

ARIB Association of Radio Industry and Business

AWG APT Wireless Group

CPE Department of Chemical Process Engineering

DSM Department of Standards Malaysia, MOSTI

EGT Division of Environment and Green Technology

EoGS Education on Global Standard

EoGSz Education on Global Standardization

ESE Department of Electronic and System Engineering

FRAND Fair, Reasonable and Non Discriminatory Licensing

GITI Global Information and Telecommunication Institute, Waseda University

GS Global Standard

GSz Global Standardization

ICT Information and Communication Technology

IEC International Electrotechnical Commission

IEEE Institute of Electric and Electrical Engineers

IETF Internet Engineering Task Force

IPR Intellectual Property Rights

IS International Standard

ISz International Standardization

ISC Industrial Standards Committees

ISO International Organization for Standardization

ITU International Telecommunication Union

JSA Japan Standard Association

JUC Japan University Consortium

MCMC Malaysian Communications and Multimedia Commission

METI Ministry of Economy, Trade and Industry 
82 H. Nakanishi et al.

List of Abbreviations

MIC Ministry of Internal affairs and Communications

MJIIT Malaysia-Japan International Institute of Technology

MOSTI Ministry of Science and Technology Innovation

MOT Department of Management of Technology

MPE Department of Mechanical Precision Engineering

RAND Reasonable and Non Discriminatory Licensing

SIRIM Standards and Industrial Research Institute of Malaysia Berhad

SKMM Suruhanjaya Komunikasi Dan Multimedia Malaysia

SME Small and Medium-sized Enterprise

TBT Technical Barriers of Trade

TC Technical Committee

TTC Telecommunication Technology Commission

UTM Universiti Teknologi Malaysia

WG Working Group

WTO World Trade Organization 